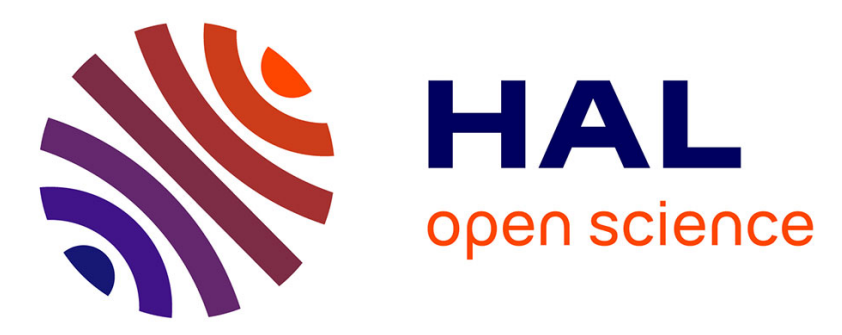

\title{
Direct Visualization of Local Spin Transition Behaviors in Thin Molecular Films by Bimodal AFM
}

Victoria Shalabaeva, Alin-Ciprian Bas, Mario Piedrahita-Bello, Karl Ridier, L. Salmon, Christophe Thibault, William Nicolazzi, Gábor Molnár, Azzedine Bousseksou

\section{To cite this version:}

Victoria Shalabaeva, Alin-Ciprian Bas, Mario Piedrahita-Bello, Karl Ridier, L. Salmon, et al.. Direct Visualization of Local Spin Transition Behaviors in Thin Molecular Films by Bimodal AFM. Small, 2019, 15 (47), pp.1903892. 10.1002/smll.201903892 . hal-03019905

\section{HAL Id: hal-03019905 https://hal.science/hal-03019905}

Submitted on 23 Nov 2020

HAL is a multi-disciplinary open access archive for the deposit and dissemination of scientific research documents, whether they are published or not. The documents may come from teaching and research institutions in France or abroad, or from public or private research centers.
L'archive ouverte pluridisciplinaire HAL, est destinée au dépôt et à la diffusion de documents scientifiques de niveau recherche, publiés ou non, émanant des établissements d'enseignement et de recherche français ou étrangers, des laboratoires publics ou privés. 


\section{WILEY-VCH}

Direct visualization of local spin transition behaviors in thin molecular films by bimodal AFM

Victoria Shalabaeva, Alin-Ciprian Bas, Mario Piedrahita-Bello, Karl Ridier, Lionel Salmon, Christophe Thibault, William Nicolazzi, Gábor Molnár, * and Azzedine Bousseksou*

Dr. V. Shalabaeva, Dr. A.-C. Bas, M. Piedrahita-Bello, Dr. K. Ridier, Dr. L. Salmon, Prof. W. Nicolazzi, Dr. G. Molnár, Dr. A. Bousseksou

LCC, CNRS and Université de Toulouse, UPS, INP, F-31077 Toulouse, France

E-mail: gabor.molnar@lcc-toulouse.fr, azzedine.bousseksou@lcc-toulouse.fr

Dr. A.-C. Bas, Prof. C. Thibault

LAAS, CNRS and Université de Toulouse, INSA, UPS, F-31077 Toulouse, France

Keywords: spin-crossover, thin films, atomic force microscopy, viscoelastic mapping, strain

Thin films of the molecular spin crossover complex $\left[\mathrm{Fe}\left(\mathrm{HB}(1,2,4 \text {-triazol-1-yl })_{3}\right)_{2}\right]$ undergo spin transition above room temperature, which can be exploited in sensors, actuators and information processing devices. Variable temperature viscoelastic mapping of the films by atomic force microscopy reveals a pronounced decrease of the elastic modulus when going from the low spin $(5.2 \pm 0.4 \mathrm{GPa})$ to the high spin $(3.6 \pm 0.2 \mathrm{GPa})$ state, which is also accompanied by increasing energy dissipation. This technique allows us to image, with high spatial resolution, the formation of high spin puddles around film defects, which we ascribe to local strain relaxation. On the other hand, no clustering process due to cooperative phenomena could be observed. This experimental approach sets the stage for the investigation of the spin transition at the nanoscale, including phase nucleation and evolution as well as local strain effects.

Spin crossover (SCO) complexes, displaying a reversible transformation between the low-spin (LS) and high-spin (HS) states of the central metal ion, represent a classical example of magnetic molecular switches. ${ }^{[1-3]}$ Recently, much attention has been attracted to emergent physical properties and potential applications of nanoscale SCO materials in the form of nanoparticles, thin films and nano-heterostructures. ${ }^{[4-6]}$ Many aspects of the related physics focus on the study of the effect of surfaces/interfaces on the phase stability and phase transition 


\section{WILEY-VCH}

dynamics. ${ }^{[7-12]}$ At reduced sizes, the increasing contribution of surfaces to the total free energy may give rise to structural and electronic changes in the material, which actually go beyond the surface layers. The surface/interface energy can be therefore viewed as a key parameter, which governs the SCO properties at the nanoscale. ${ }^{[7]}$ Understanding surface/interface phenomena is not only important to elucidate nanoscale SCO behaviors, but it also opens up possibilities for engineering these nanomaterials. ${ }^{[12-19]}$ However, thin films and nanostructures usually have non-uniform properties due to defects, grain boundaries, strain distributions and so forth. There is therefore a need towards the assessment of these effects on a sub-micron scale from spatially resolved techniques.

Scanning probe microscopy (SPM) provides an attractive means for quantitative and noninvasive studies of local phase change behaviors in various materials under external stimuli (magnetic and electric fields, temperature, light irradiation, etc.). Solid-solid phase transitions in thin films can be visualized through different material properties (e.g. magnetic, optical, electrical, thermal, mechanical and electromechanical) by SPM techniques such as piezoresponse force microscopy $(\mathrm{PFM}),{ }^{[20]}$ Kelvin probe force microscopy $(\mathrm{KPFM}),{ }^{[21]}$ scanning near-field optical microscopy (SNOM), ${ }^{[22]}$ scanning tunneling microscopy (STM), ${ }^{[12]}$ scanning microwave microscopy (SMM) ${ }^{[23]}$ and magnetic force microscopy (MFM). ${ }^{[24]}$

In the case of thin SCO films, we have recently demonstrated that AFM force spectroscopy allows the spin transition to be probed with high spatial resolution. ${ }^{[25]}$ This approach is based on the ubiquitous decrease of the elastic modulus of SCO materials (by ca. 10-50\%) when going from the LS to the HS phase. ${ }^{[26]}$ In this communication, we exploit this property to assess the effect of film inhomogeneity on the local SCO behavior in thin films of the compound [Fe(HB(1,2,4-triazol-1-yl) $\left.\left.)_{2}\right)_{2}\right]$ (compound 1) using fast, quantitative, non-invasive AFM nanomechanical mapping.

Compound 1 is a molecular SCO complex, ${ }^{[27]}$ which undergoes a robust, isostructural, firstorder spin transition near $334 \mathrm{~K}$ in macroscopic single crystals. ${ }^{[28,29]}$ Recently, we have shown 


\section{WILEY-VCH}

that very high quality, nanocrystalline films of $\mathbf{1}$ can be obtained by vacuum thermal evaporation followed by solvent vapor annealing. ${ }^{[30,31]}$ These films exhibit a well-reproducible thermal SCO (similar to the bulk material) as well as an ultrafast $\left(\sim 10^{-13} \mathrm{~s}\right)$ light-induced spin state switching at room temperature. ${ }^{[32]}$ With decreasing film thickness, the transition is slightly shifted to higher temperatures, which we attributed to the stabilization of the LS phase by surface energy and stress. ${ }^{[19]}$ The transition in the films is accompanied by a substantial spontaneous strain and associated changes of refractive index and electrical resistance, which gives rise to numerous potential applications of $\mathbf{1}$ in mechanical actuators, temperature sensors, photonic and electronic devices. ${ }^{[6,26,33-35]}$

For the present work, a $400 \mathrm{~nm}$ thick film of $\mathbf{1}$ was grown on a Si substrate and investigated by bimodal (AM-FM) imaging. This technique combines the features and benefits of conventional amplitude modulated (AM) tapping mode with a quantitative and highly sensitive frequency modulated (FM) second mode, which we use for mapping viscoelastic properties (see Figure 1a). ${ }^{[36-38]}$ To put it simply, the second mode frequency shift can be related to the sample stiffness, while changes in the second mode amplitude give information on energy dissipation.

In order to obtain quantitative mechanical information, the geometry of the tip (in particular, the tip radius) must be accurately determined. The standard protocol of measuring material stiffness with AFM implies a measurement of a reference sample (in general polystyrene) with known elastic modulus prior to the experiment and the extraction of the tip radius value using Hertzian contact mechanics. ${ }^{[37]}$ However, the study of mechanical properties across a phase transition requires the acquisition of a large amount of scans at different temperatures. In particular, the wear of the tip as well as its contamination represent an important issue and make quantitative studies challenging. ${ }^{[39]}$ For the present analysis, we have thus implemented an internal referencing method, which consists in scanning the film of $\mathbf{1}$ together with a codeposited epoxy-based film (SU-8) with a known modulus in the temperature range of interest. $^{[40]}$ This 'internal reference' allows calibration of the tip radius in situ for each scan, 


\section{WILEY-VCH}

which ensures accurate measurements and considerably reduces the measurement time (see the Supporting Information, SI, for more experimental details).

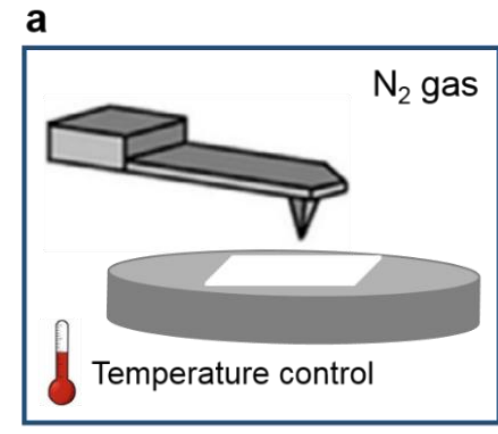

b

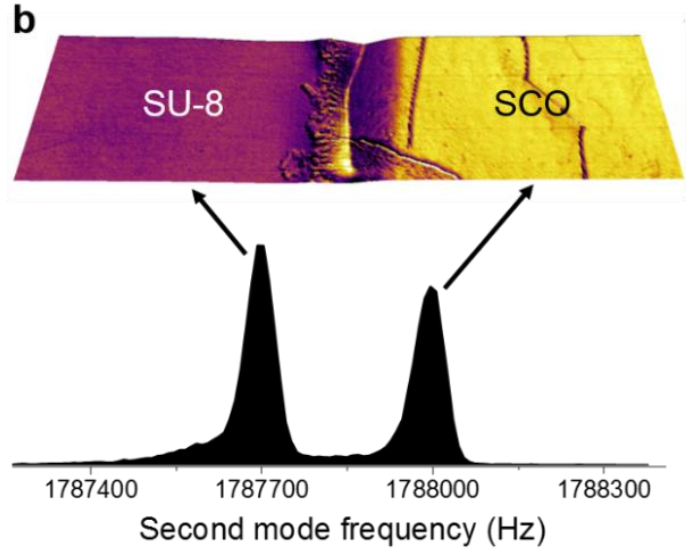

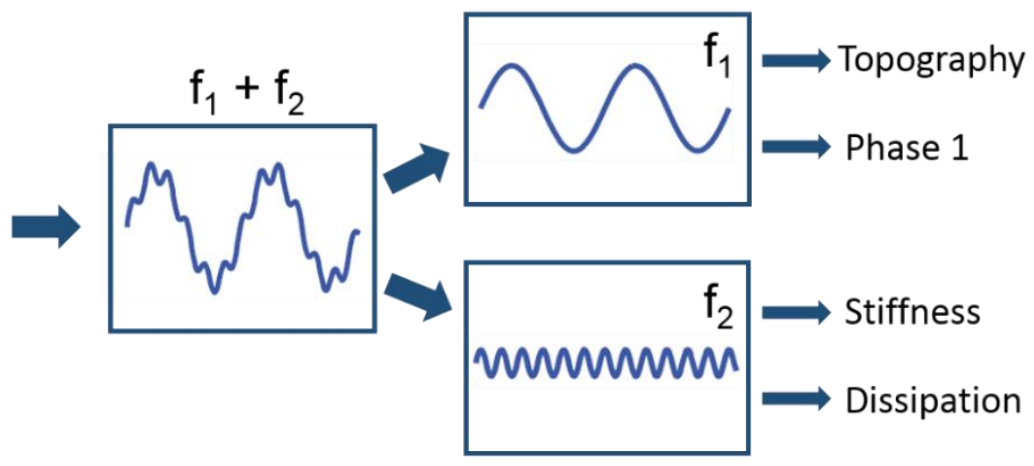

C
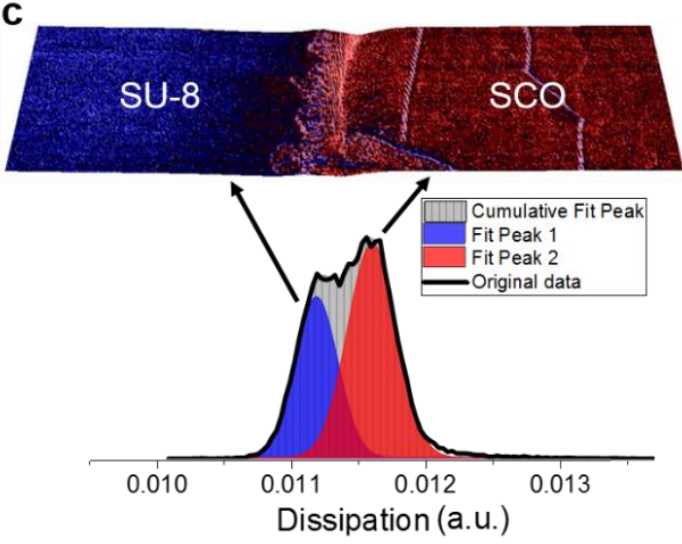

Figure 1. (a) Scheme of the AM-FM viscoelastic mapping. (Adapted with permission. ${ }^{[36]}$ Copyright 2017 American Chemical Society.) Maps of the second mode frequency (b) and energy dissipation (c) overlaid on topography for a SU-8/SCO film. The histograms below correspond to the complete AFM scan area. Scan size $14 \times 3.5 \mu \mathrm{m}^{2}$.

Temperature-dependent AM-FM analysis was performed between $303 \mathrm{~K}$ and $373 \mathrm{~K}$ in heating and cooling modes using a Cypher-ES AFM instrument (Oxford Instruments) and reflective Au-coated Si probes (NANOSENSORS ${ }^{\text {TM }}$ PPP-NCHAu). To minimize artefacts from water adsorbates, prior to experiments, the AFM chamber was purged with dry nitrogen gas while heating the sample to $373 \mathrm{~K}$ for $15 \mathrm{~min}$ in order to dehydrate the sample. Figures $\mathbf{1 b}$ and 1c display maps of the cantilever's second resonance frequency $\left(f_{r 2}\right)$ and of the energy dissipation obtained for the SU-8/SCO sample at $303 \mathrm{~K}$. The histograms of both parameters evidence a clear distinction between two materials. Increasing value of $f_{r 2}$ corresponds to a higher storage 


\section{WILEY-VCH}

modulus $\left(E^{\prime}=5.4 \mathrm{GPa}\right)$ of 1 with respect to SU-8 $\left(E^{\prime}=3.4 \mathrm{GPa}\right)$, while the enhanced energy dissipation denotes a higher loss modulus $(E ”)$ in $\mathbf{1 .}$

Figure 2a shows the storage modulus maps of the SU-8/SCO sample at selected temperatures during a complete heating-cooling cycle. The two materials show very different behaviors as the temperature is ramped from $303 \mathrm{~K}$ to $373 \mathrm{~K}$. Remarkably, a substantial drop of $E$ ' occurs in the SCO film around the spin transition temperature $(338 \mathrm{~K})$, as evidenced by a sudden change of contrast with respect to the SU-8 reference sample. Figure $2 \mathbf{c}$ shows the mean values of $E^{\prime}$ for the SU-8 and the SCO films as a function of temperature for a full thermal cycle. Within the error bars, these values turned out to be well reproducible over numerous measurement cycles $(>10)$ conducted within a period of several months. In the pure LS $(<323$ $\mathrm{K})$ and $\mathrm{HS}(>343 \mathrm{~K}$ ) states the mean elastic moduli are $5.2 \pm 0.4 \mathrm{GPa}$ and $3.6 \pm 0.2 \mathrm{GPa}$, respectively. The good reproducibility of the measurements as well as the excellent match between the transition temperatures determined by AFM and by far-field optical absorbance measurements (Figure 2b) clearly prove the non-invasive nature of our AFM measurement protocol.

The pronounced softening of the film when going from the LS to the HS state is in good agreement with previous results obtained on bulk and thin film samples of $\mathbf{1}$ by nuclear inelastic scattering and micromechanical measurements, respectively (see Table 1). ${ }^{[26]}$ On the other hand, one may note that the absolute values of elastic moduli are significantly smaller in our AFM measurements. This discrepancy is often encountered in AFM nanomechanical measurements for various reasons. ${ }^{[41]}$ First, measurement uncertainties are relatively high for each method (in the GPa range). More fundamentally, the storage and Young's moduli of viscoelastic materials are in general comparable, but never match. In addition, near surface elastic properties may differ significantly from those of the bulk material due to surface relaxation/reconstruction, oxidation, presence of adsorbates, and so forth. In our case, the strong anisotropy of the oriented crystalline films must be also taken into account. ${ }^{[30]}$ In fact, the elastic modulus is probed by 


\section{WILEY-VCH}

the AFM along the $c$-axis of the orthorhombic crystal lattice of $\mathbf{1}$, while the other methods average the stiffness along different crystallographic axes.
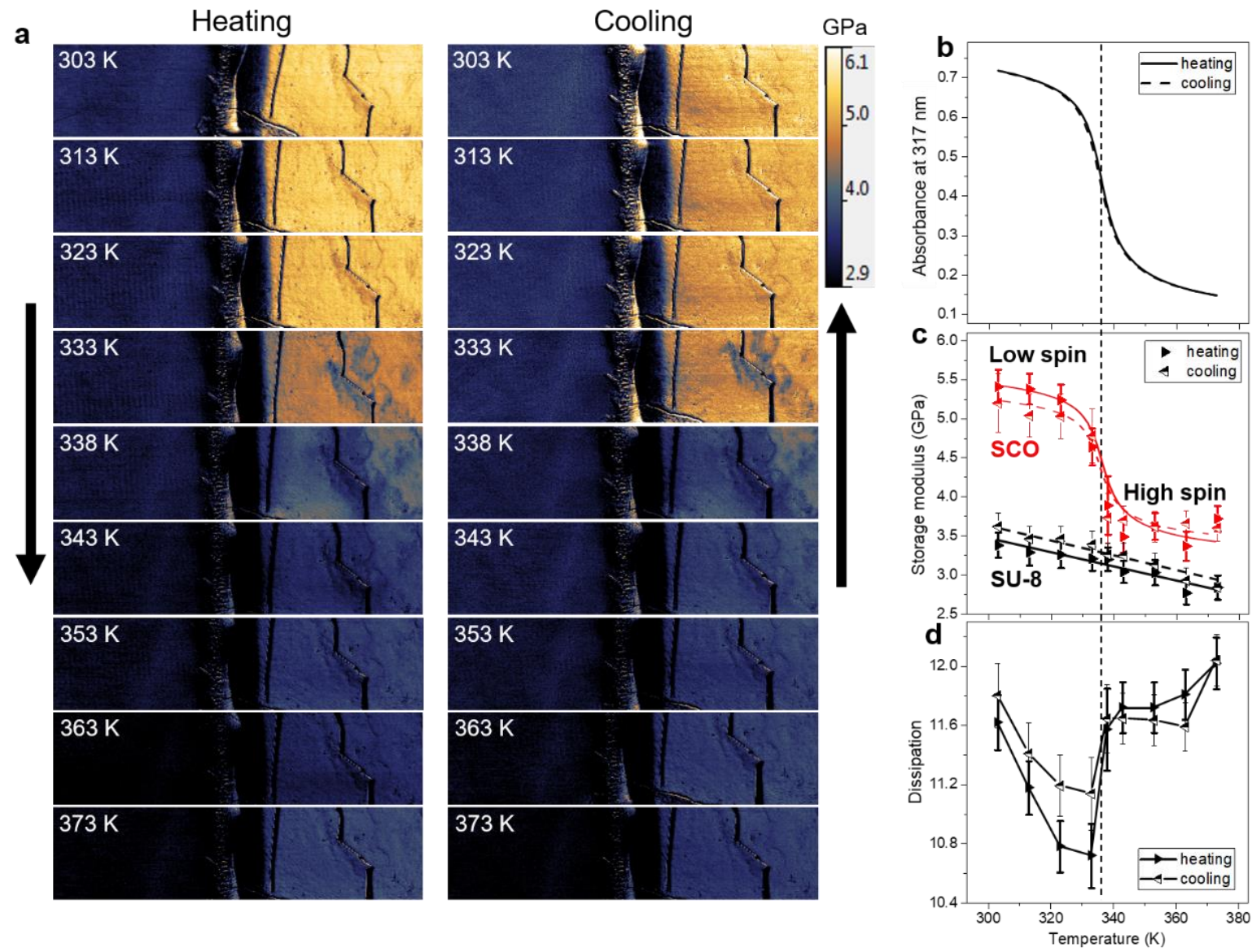

Figure 2. (a) Storage modulus $\left(E^{\prime}\right)$ maps of the SU-8 and $\left[\mathrm{Fe}\left(\mathrm{HB}(\mathrm{tz})_{3}\right)_{2}\right]$ films across the spin transition temperature range in the heating and cooling modes. The image size is $14 \times 3.5 \mu \mathrm{m}^{2}$. (b) Thermal spin transition curve of the $\left[\mathrm{Fe}\left(\mathrm{HB}(\mathrm{tz})_{3}\right)_{2}\right]$ film obtained by far-field optical absorption measurements. (c) Temperature dependence of the mean values of the storage moduli for the two materials, extracted from the AFM images in Figure 2a. (d) Temperature dependence of the energy dissipation in $\left[\mathrm{Fe}\left(\mathrm{HB}(\mathrm{tz})_{3}\right)_{2}\right]$. (Lines are added as guides for the eyes.)

Table 1. Comparison of reported elastic moduli of $\mathbf{1 .}$

\begin{tabular}{lccc}
\hline \multicolumn{2}{l}{ Elastic modulus [GPa] } & Method & Sample \\
\hline $10.9 \pm 1.0$ & $7.1 \pm 0.5$ & Nuclear inelastic scattering & \\
& High spin & Crystalline powder \\
$12.0 \pm 1.4$ & $9.9 \pm 1.4$ & Microcantilever bending & Crystalline film \\
$5.3 \pm 0.4$ & $3.6 \pm 0.2$ & Viscoelastic AFM (this work) & Crystalline film \\
\hline
\end{tabular}




\section{WILEY-VCH}

Figure 2d shows the temperature dependence of the energy dissipation in 1. Remarkably, increasing dissipation can be depicted near the spin transition temperature (ca. $338 \mathrm{~K})$. As such, the results in Figure $2 d$ are indicative of significant internal frictions during the spin transition and a more viscous HS phase.

A closer inspection of the storage modulus maps at 333 and $338 \mathrm{~K}$ in Figure 2a recorded in the course of the spin transition reveals a LS/HS phase separation - reminiscent of nucleation and growth phenomena - taking place next to film imperfections (i.e. cracks, crevices or holes). Driven by the aim to better understand the physical mechanism causing this observation, we performed a more careful analysis in a small area around a crack. Figure 3a depicts the storage modulus maps acquired by $3 \mathrm{~K}$ steps between 328 and $343 \mathrm{~K}$ with a resolution of $7 \mathrm{~nm} /$ pixel. The histograms extracted from the maps of moduli clearly reveal the coexistence of two phases. At $331 \mathrm{~K}$, one may notice the appearance of a second peak that monotonously grows through the phase transition. At the same time, the first peak monotonously shrinks and disappears around $340 \mathrm{~K}$. (This observation was repeatedly made on the same area for more than five heating-cooling cycles). At first sight, this behavior seems to be similar to the mechanism seen in macroscopic crystals of $\mathbf{1}$, where the spin-state switching within the thermal hysteresis region occurs via a nucleation and growth process. ${ }^{[29]}$ In our case, however, the examination of the cooling cycle (Figure 2a) does not show any sign of LS phase nucleation. In particular, at 333 $\mathrm{K}$ the area around the crack is still in the HS state. We can thus conclude that the formation of these HS "puddles" around the crack does not denote a nucleation process; instead, it corresponds to a lowering of the spin transition temperature. This is particularly clear in Figure $3 \mathrm{~b}$, which displays the temperature dependence of the two elastic moduli peaks: the transition curve corresponding to the surface area near the crack (denoted 'Peak 2') is downshifted by about $3 \mathrm{~K}$. Interestingly, this shift is approximately of the same order of magnitude - with opposite sign - as the variation of the spin transition temperature with decreasing film thickness. Indeed, in a previous work we have shown that when decreasing the thickness of films of $\mathbf{1}$, the 


\section{WILEY-VCH}

LS state is progressively stabilized due to its lower surface/interface energy and stress. ${ }^{[19]} \mathrm{We}$ can thus suggest that cracks relieve the surface stress effects and thus restore the HS state in the film by a strain relaxation mechanism. This stabilization appears efficient up to the micrometer range around the crack, suggesting that lithographic patterning of the films should lead to a modulation of their spin transition temperature.

a
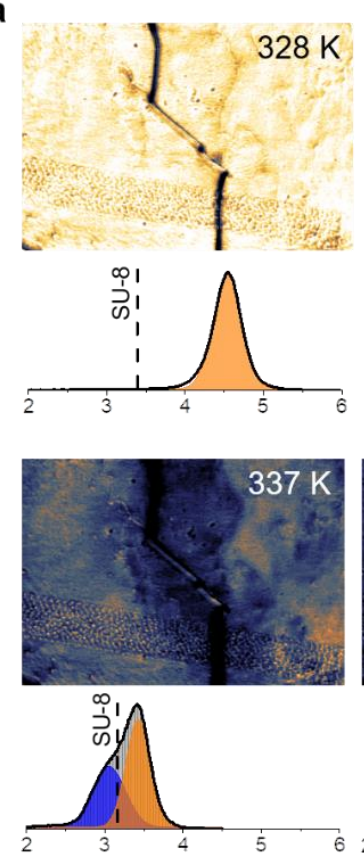
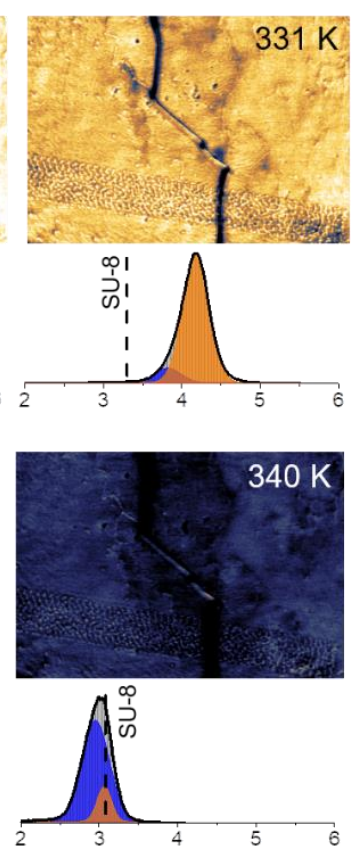
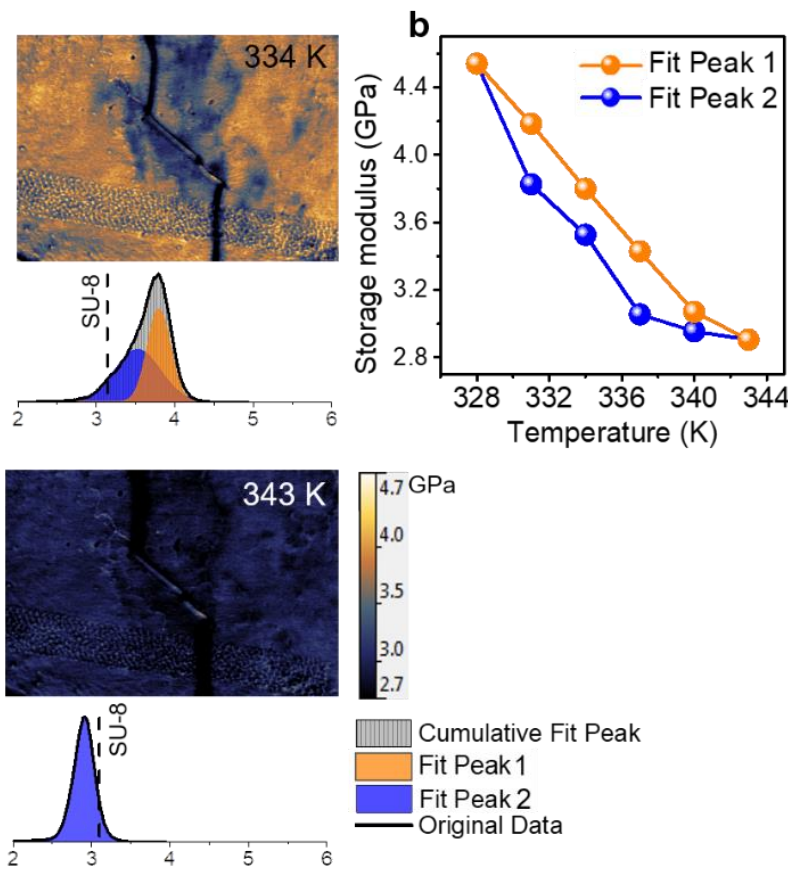
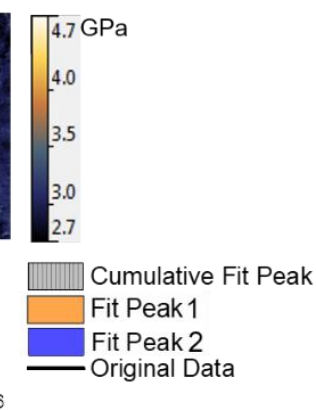

Figure 3. (a) Storage modulus maps around a film defect acquired between 328 and $343 \mathrm{~K}$. Histograms of the modulus maps (corresponding to the complete scan area) show the coexistence of two zones, characterized by different SCO behaviors. Scan size is $5 \times 3.5 \mu \mathrm{m}^{2}$. (b) Temperature dependence of the fitted storage modulus peaks.

The present AFM experiments provide also crucial information for understanding the nature of the phase transition in the films of $\mathbf{1}$. It is well known that the large transformation strain, which accompanies the SCO, may lead to the emergence of discontinuous (first-order) phase transitions. ${ }^{[42-44]}$ Indeed, in high-quality single crystals of $\mathbf{1}$, using far-field optical microscopy, we have repeatedly observed a heterogeneous nucleation, followed by the formation of a fast moving HS/LS phase boundary, leading to a discontinuity at the transition. ${ }^{[29]}$ Yet, an important aspect of this transition has escaped our attention. As shown in Figure 4, the discontinuity accounts for only ca. $60 \%$ of the transition and, actually, the rest of the molecules in the crystal 


\section{WILEY-VCH}

change their spin state in a rather gradual and spatially homogenous manner before as well as after the discontinuity. In other words, the SCO in single crystals of $\mathbf{1}$ is of first order, though it is certainly very close to the crossover regime.
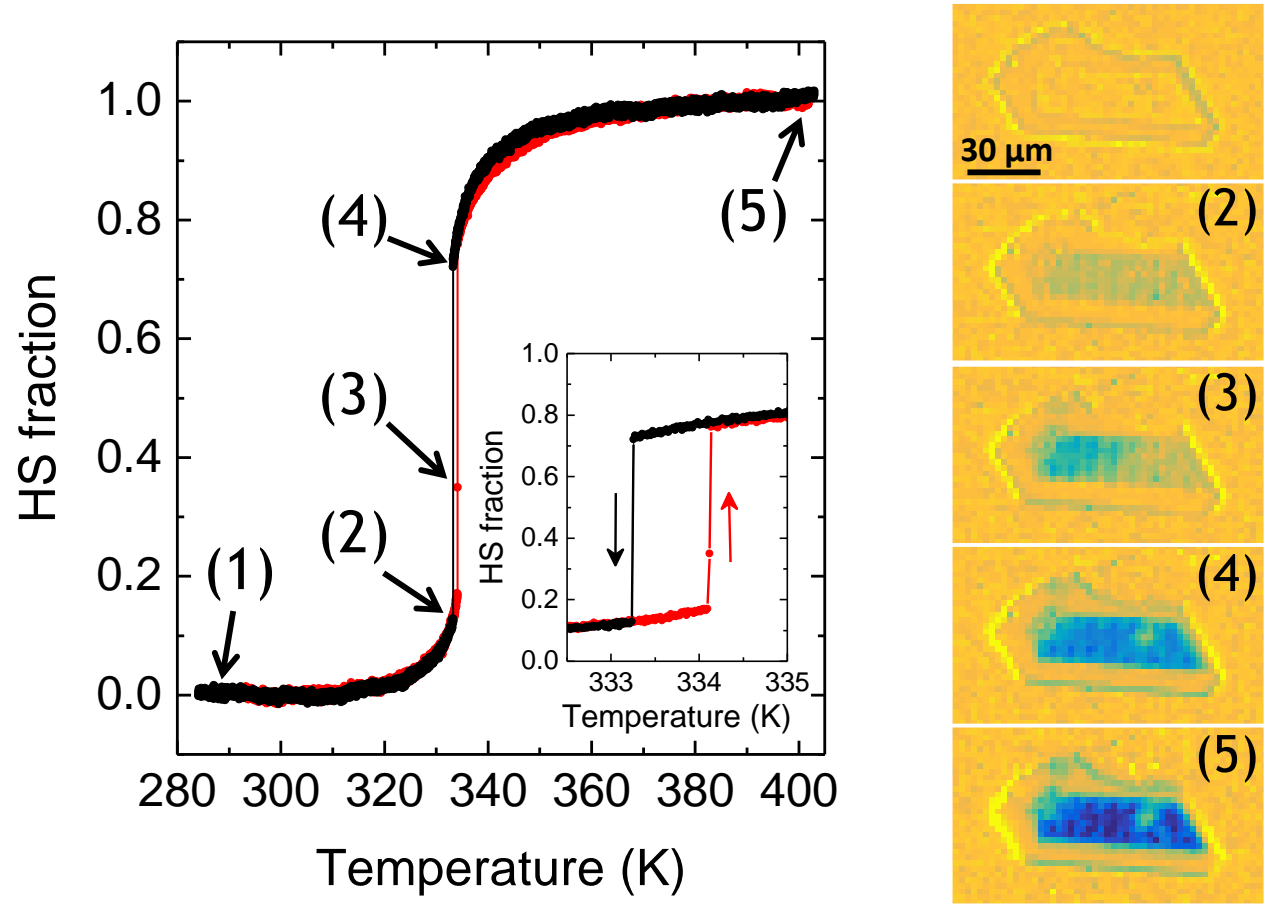

Figure 4. Optical microscopy study of a single crystal of $\mathbf{1}$ across the spin transition. (Left) Temperature dependence of the HS fraction in a crystal obtained from the spatially averaged optical transmission at $\lambda=543 \mathrm{~nm}$ during one heating-cooling cycle $(2 \mathrm{~K} / \mathrm{min})$. The inset shows a magnified version of the thermal hysteresis loop. (Right) Selected optical microscopy snapshots of the crystal at different stages of the transition in the heating mode: (1) $n_{H S}=0,(2)$ $\mathrm{n}_{\mathrm{HS}}=0.17,(3) \mathrm{n}_{\mathrm{HS}}=0.35$, (4) $\mathrm{n}_{\mathrm{HS}}=0.76$ and (5) $\mathrm{n}_{\mathrm{HS}}=1$. Blue and dark yellow (artificial) colors indicate the HS and LS phases, respectively.

At first sight, the spin transition curve of the thin film of $\mathbf{1}$, obtained by far-field optical microscopy (Figure 2b), is reminiscent to that of the bulk crystal (Figure 4). In particular, a thermal hysteresis loop of $c a .0 .5 \mathrm{~K}$ width is reproducibly observed for the films (see ref. 19 for more details), which is a mark of a first-order transition. On the other hand, no discontinuity can be discerned in the case of the films. However, the films consist of a large number of tiny crystals (of $c a .50 \mathrm{~nm}$ mean size) ${ }^{[30]}$ with a distribution of the transition temperatures, which can mask the discontinuity. The high-resolution AFM images across the phase transition in Figure 2 and 3 allow us to reduce this distribution effect and reveal that the transition in the 


\section{WILEY-VCH}

films is indeed not discontinuous anymore. Instead, within the resolution of our measurements, one can observe a spatially homogenous SCO, which occurs in a continuous manner. We can thus suggest that the film stress and/or defects alter the intrinsically first-order transition to become a gradual spin crossover. Finally, it is worth noting that no sign of nucleation and growth phenomena - indicative of transmission of cooperative interactions through the grain boundaries - were detected in the AFM images, which is in line with the proposed nature of the SCO in the films.

In conclusion, we have presented a spatially resolved investigation of the spin transition in $\left[\mathrm{Fe}\left(\mathrm{HB}(\mathrm{tz})_{3}\right)_{2}\right]$ thin films through the quantitative mapping of their viscoelastic properties by AFM. This approach enabled us to detect - in a reproducible and non-invasive manner - a ca. $30 \%$ decrease of the elastic modulus when going from the LS to the HS state. As it was demonstrated in several recent reports, the spatial resolution of this technique can reach the 1$10 \mathrm{~nm}$ range for various samples, ${ }^{[45-46]}$ which opens up a unique possibility to assess mechanical properties of SCO materials at the nanoscale, with particular relevance to their possible use in nanoscale actuator devices. ${ }^{[26,33]}$ The ability of AFM to provide spatially resolved information on local SCO behaviors allowed us to evidence a very homogenous phase transformation in the films, except for the vicinity of film defects, which were shown to stabilize the HS state in the form of sub-micrometric puddles. This phenomenon, ascribed to strain relaxation, is important when considering the use of these films for sensing and imaging purposes and suggests that strain engineering should allow for tuning the local and/or global spin transition temperature in thin films. The nature of the spin transition in the films was also discussed in light of these results, which allowed us to conclude that the bulk, first-order transition becomes a continuous crossover in the nanocrystalline films. It would be interesting to modulate the stress state of the films between tensile and compressive (e.g. by epitaxy) and observe by AFM the concomitant variation of their spin transition properties. Another interesting perspective consists of the viscoelastic mapping of SCO nanoparticle - polymer composites. In these dynamic and 


\section{WILEY-VCH}

heterogeneous systems, strain coupling plays often an important role, ${ }^{[47-48]}$ but the corresponding microscopic mechanisms remain difficult to visualize by other methods.

\section{Supporting Information}

Supporting Information is available from the Wiley Online Library or from the author.

\section{Acknowledgements}

The PhD grants of ACB and MPB were financed by the Occitanie Région and the Federal University of Toulouse. We are indebted to Rafael Barbatini and Roger Proksch (Asylum Research) for their kind help in the analysis of the experimental data.

Received: ((will be filled in by the editorial staff))

Revised: ((will be filled in by the editorial staff)) Published online: ((will be filled in by the editorial staff))

\section{References}

[1] Spin Crossover in Transition Metal Compounds I-III, (Eds: P. Gütlich, H. A.

Goodwin), Springer, Berlin Heidelberg 2004.

[2] Spin-Crossover Materials: Properties and Applications, (Eds: M. A. Halcrow), John Wiley \& Sons, Oxford, UK 2013.

[3] Spin Crossover Phenomenon, (Eds: A. Bousseksou), C. R. Chimie 2018, 21, pp. 10551300.

[4] A. Bousseksou, G. Molnár, L. Salmon, W. Nicolazzi, Chem. Soc. Rev. 2011, 40, 3313.

[5] K. S. Kumar, M. Ruben, Coord. Chem. Rev. 2017, 346, 176.

[6] G. Molnár, S. Rat, L. Salmon, W. Nicolazzi, A. Bousseksou, Adv. Mater. 2018, 30, 1703862.

[7] G. Félix, W. Nicolazzi, L. Salmon, G. Molnár, M. Perrier, G. Maurin, J. Larionova, J. Long, Y. Guari, A. Bousseksou, Phys. Rev. Lett. 2013, 110, 235701.

[8] A. Slimani, K. Boukheddaden, K. Yamashita, Phys. Rev. B 2014, 89, 214109.

[9] D. Chiruta, J. Linares, S. Miyashita, K. Boukheddaden, J. Appl. Phys. 2014, 115, 194309. 


\section{WILEY-VCH}

[10] G. Félix, W. Nicolazzi, M. Mikolasek, G. Molnár, A. Bousseksou, Phys. Chem. Chem. Phys. 2014, 16, 7358.

[11] M. Mikolasek, W. Nicolazzi, F. Terki, G. Molnár, A. Bousseksou, Phys. Chem. Chem. Phys. 2017, 19, 12276.

[12] K. Bairagi, O. Iasco, A. Bellec, A. Kartsev, D. Li, J. Lagoute, C. Chacon, Y. Girard, S. Rousset, F. Miserque, Y. J. Dappe, A. Smogunov, C. Barreteau, M.-L. Boillot, T. Mallah, V. Repain, Nat. Commun. 2016, 7, 12212.

[13] T. G. Gopakumar, M. Bernien, H. Naggert, F. Mationo, C. Hermanns, A. Bannwarth, S. Mühlenberend, A. Krüger, D. Krüger, F. Nickel, W. Walter, R. Berndt, W. Kuch, F. Tuczek, Chem. Eur. J. 2013, 19, 15702.

[14] C. R. Gros, M. K. Peprah, B. D. Hosterman, T. V. Brinzari, P. A. Quintero, M. Sendova, M. W. Meisel, D. R. Talham, J. Am. Chem. Soc. 2014, 136, 9846.

[15] D. M. Pajerowski, J. E. Gardner, F. A. Frye, M. J. Andrus, M.F. Dumont, E. S. Knowles, M. W. Meisel, D. R. Talham, Chem. Mater. 2011, 23, 3045.

[16] A. Akou, C. Bartual-Murgui, K. Abdul-Kader, M. Lopes, G. Molnár, C. Thibault, C. Vieu, L. Salmon, A. Bousseksou, Dalton Trans. 2013, 42, 16021.

[17] L. Kipgen, M. Bernien, S. Ossinger, F. Nickel, A. J. Britton, L. M. Arruda, H. Naggert, C. Luo, C. Lotze, H. Ryll, F. Radu, E. Schierle, E. Weschke, F. Tuczek, W. Kuch, Nat. Commun. 2018, 8, 2984.

[18] V. Rubio-Gimenez, C. Bartual-Murgui, M. Galbiati, A. Nunez-Lopez, J. Castells-Gil, B. Quinard, P. Seneor, E. Otero, P. Ohresser, A. Cantarero, E. Coronado, J. A. Real, R. Mattana, S. Tatay, C. Marti-Gastaldo, Chem. Sci. 2019, 10, 4038.

[19] V. Shalabaeva, M. Mikolasek, M. D. Manrique-Juarez, A. C. Bas, S. Rat, L. Salmon, W. Nicolazzi, G. Molnár, A. Bousseksou, J. Phys. Chem. C 2017, 121, 25617. 


\section{WILEY-VCH}

[20] C. W. Bark, P. Sharma, Y. Wang, S. H. Baek, S. Lee, S. Ryu, C. M. Folkman, T. R.

Paudel, A. Kumar, S. V. Kalinin, A. Sokolov, E. Y. Tsymbal, M. S. Rzchowski, A.

Gruverman, C. B. Eom, Nano Lett. 2012, 12, 1765.

[21] C. Ko, Z. Yang, S. Ramanathan, ACS Appl. Mater. Interfaces 2011, 3, 3396.

[22] M. Lopes, C. M. Quintero, E. M. Hernández, V. Velazquez, C. Bartual-Murgui, W.

Nicolazzi, L. Salmon, G. Molnár, A. Bousseksou, Nanoscale 2013, 5, 7762.

[23] A. Tselev, E. Strelcov, I. A. Luk'yanchuk, J. D. Budai, J. Z. Tischler, I. N. Ivanov, K. Jones, R. Proksch, S. V. Kalinin, A. Kolmakov, Nano Lett. 2010, 10, 2003.

[24] S. Schreiber, M. Savla, D. V. Pelekhov, D. F. Iscru, C. Selcu, P. C. Hammel, G. Agarwal, Small 2008, 4, 270.

[25] E. M. Hernández, C. M. Quintero, O. Kraieva, C. Thibault, C. Bergaud, L. Salmon, G. Molnár, A. Bousseksou, Adv. Mater. 2014, 26, 2889.

[26] M. Mikolasek, M. D. Manrique-Juarez, H. J. Shepherd, K. Ridier, S. Rat, V. Shalabaeva, A.-C. Bas, I. E. Collings, F. Mathieu, J. Cacheux, T. Leichle, L. Nicu, W. Nicolazzi, L. Salmon, G. Molnár, A. Bousseksou, J. Am. Chem. Soc. 2018, 140, 8970.

[27] S. Trofimenko, J. Am. Chem. Soc. 1967, 89, 3170.

[28] S. Rat, K. Ridier, L. Vendier, G. Molnár, L. Salmon, A. Bousseksou, CrystEngComm 2017, 19, 3271.

[29] K. Ridier, S. Rat, H. J. Shepherd, L. Salmon, W. Nicolazzi, G. Molnár, A. Bousseksou, Phys. Rev. B 2017, 96, 134106.

[30] V. Shalabaeva, S. Rat, M. D. Manrique-Juarez, A.-C. Bas, L. Vendier, L. Salmon, G. Molnár, A. Bousseksou, J. Mater. Chem. C 2017, 5, 4419.

[31] A.-C. Bas, V. Shalabaeva, X. Thompson, L. Vendier, L. Salmon, L. Routaboul, G. Molnár, A. Bousseksou, C. R. Chimie 2019, 22, 525.

[32] K. Ridier, A.-C. Bas, V. Shalabaeva, W. Nicolazzi, L. Salmon, G. Molnár, A.

Bousseksou, M. Lorenc, R. Bertoni, E.Collet, H. Cailleau, Adv. Mater. 2019, 31, 1901361. 


\section{WILEY-VCH}

[33] M. D. Manrique-Juarez, F. Mathieu, V. Shalabaeva, J. Cacheux, S. Rat, L. Nicu, T. Leïchlé, L. Salmon, G. Molnár, A. Bousseksou, Angew. Chemie Int. Ed. 2017, 121, 8074.

[34] V. Shalabaeva, K. Ridier, S. Rat, M. D. Manrique-Juarez, L. Salmon, I. Séguy, A. Rotaru, G. Molnár, A. Bousseksou, Appl. Phys. Lett. 2018, 112, 013301.

[35] L. Poggini, M. Gonidec, J. H. Gonzalez-Estefan, G. Pecastaings, B. Gobaut, P. Rosa, Adv. El. Mater. 2018, 4, 1800204.

[36] M. Kocun, A. Labuda, W. Meinhold, I. Revenko, R. Proksch, ACS Nano 2017, 11, 10097.

[37] A. Labuda, M. Kocuń, W. Meinhold, D. Walters, R. Proksch, Beilstein J. Nanotechnol. 2016, 7, 970.

[38] R. Garcia, R. Proksch, Eur. Polym. J. 2013, 49, 1897.

[39] J. Liu, D. S. Grierson, N. Moldovan, J. Notbohm, S. Li, P. Jaroenapibal, S. D.

O'Connor, A. V. Sumant, N. Neelakantan, J. A. Carlisle, K. T. Turner, R. W. Carpick, Small 2010, 6,1140 .

[40] S. Chung, S. Park. J. Mech. Sci. Technol. 2013, 27, 2701.

[41] D. Passeri, M. Rossi, E. Tamburri, M. L. Terranova, Anal. Bional. Chem. 2013, 405, 1463.

[42] H. Spiering, K. Boukheddaden, J. Linares, F. Varret, Phys. Rev. B 2004, 70, 184106.

[43] K. Ridier, G. Molnár, L. Salmon, W. Nicolazzi, A. Bousseksou, Solid State Sci. 2017, 74, A1.

[44] F. Varret, C. Chong, A. Slimani, D. Garrot, Y. Garcia, A. D. Naik, in Spin-Crossover Materials: Properties and Applications, (Ed: M. A. Halcrow), John Wiley \& Sons, Oxford, UK 2013, pp. 425-441.

[45] S. Benaglia, V. G. Gisbert, A. P. Perrino, C. A. Amo, R. Garcia, Nat. Protocols, 2018, 13, 2890.

[46] S. Benaglia, C. A. Amo, R. Garcia, Nanoscale, 2019, 11, 15289. 


\section{WILEY-VCH}

[47] Y.-S. Koo, J. R. Galán-Mascarós, Adv. Mater. 2014, 26, 6785.

[48] S. Rat, M. Piedrahita-Bello, L. Salmon, G. Molnár, P. Demont, A. Bousseksou, Adv. Mater. 2018, 30, 1705275. 